\title{
Improvement of Composite Propellants Energy Using Explosive Materials
}

\author{
Amjad O. Saeed*, Nagmeldin M. Elamin ${ }^{\dagger}$ \\ *Sabighat Industrial Complex, Gama Technical Center, Sudan, Email: \\ ${ }^{\dagger}$ Defense Industries System, Advanced Industries Group, Sudan, Email:
}

\begin{abstract}
Composite propellants are energetic materials have ability to ignite, burn fast and cause several simultaneous exothermic chemical reactions which produce huge amounts of gases under high pressures and temperatures which can spread spontaneously. 1n the present study, the explosive material hexogen (Cyclo tri-methylene tri-nitramine) was used to improve the performance properties of composite propellants, especially the specific impulse. For several formulations of hexogen at different added percentages, the specific impulse was calculated using thermodynamic calculations program of composite propellants. The results given were compared with those formulations not including hexogen. It was seen that; hexogen caused a significant positive effect in the specific impulse. Accordingly, the energy of composite propellant was improved positively in the samples containing hexogen till $40 \%$ of the oxidizer ratio. Also, it was noticed that the specific impulse began to decrease gradually for the oxidizers containing more than $40 \%$ of hexogen which caused in a decreasing of composite propellant energy. Finally, it was concluded that, the use of some amount of explosive materials like hexogen can improve composite propellants energy successfully.
\end{abstract}

Key words-Composite propellant, exothermic reaction, hexogen, specific impulse, energy

\section{INTRODUCTION}

Rocket propellants are energetic materials have ability after been ignited to burn fastly and cause several simultaneous exothermic chemical reactions which produce huge amounts of gases under high pressures and temperatures and which can spread fastly and spontaneously. Solid propellants are used for rocket motors. Rocket motors are the simplest of all rocket designs. They consist of a casing, usually steel, filled with a mixture of solid compounds (fuel and oxidizer), which burn at a rapid rate, expelling hot gases from a nozzle to produce thrust. When ignited, solid propellant burns from the center out towards the sides of the casing. The shape of the center channel determines the rate and pattern of the burn, thus providing a means to control thrust [1].

\section{A. Hexogen cyclonite (RDX)}

Hexogen is one of the most powerful blasting explosives. Its widely applied as a military explosive both individually (in form of different charges) and as a component of many explosive compositions. Cyclo tri-methylene tri-nitramine, 1,3,5trinitro-1, 3, 5-triazacyclohexane(C3H6N6O6) [2].

\section{B. Solid Propellant Ingredients Binders:}

Pre-polymer: HTPB has been the favorite binder in recent years, because it allows a some what higher solids fraction ( 88 to $90 \%$ of $\mathrm{AP}$ and $\mathrm{Al}$ ) and relatively good physical properties at the temperature limits. It has hydroxyl value about 7.0104eq/g [3].

Plasticizers: The plasticizer in formulation is diisoctyl sebacate (DIOS) accounting for $23 \%$ of the binder and curing agent [3].
Curing Agents or Crosslinkers: TDI is selected as crosslinking agent. Its purity is greater than $98 \%$ and the isomer ratio is $35 / 65$ [4].

Bonding agent: The bonding agent is also named as coupling agent. It can react with the surface of oxidizer chemically or adsorb physically. The polyaziridine-type bonding agent is prior to be selected, in which tri (2-methyl-1-aziridinyl) phosphine oxide (MAPO) is a better selection [3].

Oxidizer: The oxidizer is main component of propellant, providing oxygen for combustion. It accounts for (60 80)\% of propellant (dependent on energy characteristic of propellant). The best oxidizer is characterized by high effective oxygen component, highest possible enthalpy of formation, high density and low average molecular weight of combustion product. In formulation selects the ammonium perchlorate (AP) oxidizer, and tri-grade components: AP1 (60 80 mesh)/ AP2 (100 $140 \mathrm{mesh}) /$ AP3 $(5 \mathrm{~m} \mathrm{12m})=1 / 3 / 3$ [3]. The nitramine HMX or RDX, In formulation selects the cyclo Tri-methylene Tri-nitramine (RDX) [5].

Fuels: Aluminum powder is used as metal fuel in formulation, with the particle diameter of $16 \mathrm{~m}$ and content of $17.5 \%$ [6].

Additives: Antioxidant: Because the $\mathrm{C}=\mathrm{C}$ bond of HTPB binder is very easy to be oxidized, antioxidant essential to ensure satisfactory aging of the propellant in various ambient conditionsAbout $0.02 \%$ DPPD (N, N-diphenyl-pphenylenediamine) is used as antioxidant in formulation [7].

Processing aid: To improve the fluidity of slurry and safety behavior during the production, appropriate diluent or other processing aid need to be added sometimes. Styrene (Vinylbenze) with content of $4 \%$ (externally added) is used as diluent in formulation. And externally add about $0.05 \%$ methylsilicone to improve the process performance [3]. 


\section{Energy Characterizations}

1) Thrust.

2) Specific Impulse.

3) Characteristic Velocity [8].

\section{Combustion properties}

1) Burning Rate

2) Pressure [9].

\section{SIMULATION AND CHEMICAL MATERIAL}

\section{A. SIMULATION}

Computer Software Programs (Thermodynamic Calculations Program of Solid Composite Propellants). This program based on the calculation of thermo chemical equilibrium components:

1) The program is designed by FORTRAN 90 language.

2) The program is most suitable for thermodynamic performance calculation of composite propellants formulation.

3) It can run on the operating system windows 2000 or windows XP and it based on the DOS operating system.

4) It can be modified and updated by using FORTRAN power station 4.0.

1) Assumptions of the Program Calculation:

1) The propellants products are homogenous and invariant in composition throughout the rocket chamber and nozzle.

2) The burning of the propellant is at constant pressure.

3) The combustion products obey the ideal gas laws.

4) There is no friction.

5) There is no heat transfer across the rocket walls, so that the flow is adiabatic.

6) The flow rate of gases at the nozzle inlet is 0 .

7) The propellant flow is steady and constant.

8) Chemical equilibrium is occur within the rocket chamber, and does not shift in the nozzle.

9) The flow in the nozzle is two phase balanced, one dimensional (axial), steady and the other isentropic flow.

2) Output Parameters:

1) $\mathrm{p}$ :Pressure in throat and nozzle (Mpa).

2) $\mathrm{H}_{f}$ : Specific enthalpy of combustion products $(\mathrm{kJ} / \mathrm{kg} \cdot \mathrm{K})$.

3) $\mathrm{C}_{p}:$ Specific heat capacity at constant pressure $(\mathrm{kJ} /$ $\mathrm{kg} . \mathrm{K})$.

4) Tc : Combustion temperature (K).

5) $\mathrm{K}:$ Specific heat ratio.

6) $\mathrm{C}^{*}$ : Characteristic velocity $(\mathrm{m} / \mathrm{s})$.

7) $\mathrm{I}_{s p}:$ Specific impulse (N.s/kg).

8) $\mathrm{C}_{f}$ : Thrust coefficient.

9) Alfa: Oxygen coefficient of propellant.

10) $\mathrm{Q}_{p}$ : Combustion heat of propellant $(\mathrm{kJ} / \mathrm{kg})$.

11) $\mathrm{R}_{o u}$ : Density of propellant $(\mathrm{g} / \mathrm{cm} 3)$.

\section{B. Chemical Material}

The formulation of the propellant consists of seven compounds to make up the slurry of the propellant, each material has specific function inside the slurry. All chemical materials using to make slurry of propellant binder, oxidizer, fuel and all addition to improve the properties of propellant and their function are shown in the table. Different series of propellant compositions based on $\mathrm{AP} / \mathrm{HTPB} / \mathrm{Al}$ and RDX based compositions were formulated and theoretical performance of the composition in the respect of thermochemical properties was computed using Thermodynamic Calculations Program of Solid Composite Propellants.

TABLE I

THE MAIN FORMULATION

\begin{tabular}{llllllll}
\hline Code & AP & AL & HTPB & DOS & H & TDI & TOTAL \\
\hline Amount & 71.4 & 16.31 & 8.6 & 3.06 & 0.14 & 0.49 & $100 \%$ \\
\hline
\end{tabular}

\section{Chemical Material Formulation}

The percentage of chemical materials are calculate carefully to seven experimental to study of effect the RDX to specific impuls.

TABLE II

SHOW THE CHEMICAL MATERIAL FORMULATION

\begin{tabular}{llllllll}
\hline code & F1 & F2 & F3 & F4 & F5 & F6 & F7 \\
\hline HTPB & 8.6 & 8.6 & 8.6 & 8.6 & 8.6 & 8.6 & 8.6 \\
TDI & 0.49 & 0.49 & 0.49 & 0.49 & 0.49 & 0.49 & 0.49 \\
DOS & 3.06 & 3.06 & 3.06 & 3.06 & 3.06 & 3.06 & 3.06 \\
AP & 71.4 & 67.83 & 64.26 & 57.1 & 50 & 42.8 & 35.7 \\
RDX & 0 & 3.57 & 7.14 & 14.3 & 21.4 & 28.6 & 35.7 \\
AL & 16.31 & 16.31 & 16.31 & 16.31 & 16.31 & 16.31 & 16.31 \\
H & 0.14 & 0.14 & 0.14 & 0.14 & 0.14 & 0.14 & 0.14 \\
Total & 100 & 100 & 100 & 100 & 100 & 100 & 100 \\
\hline
\end{tabular}

\section{RESULTS AND DISCUSSIONS}

These results include specific impulse, characteristic velocity, and combustion temperature. Also these results will be discussed for various ratios of RDX and compare to that formulation without RDX.

\section{A. The Inputs Conditions of the Program}

The simulation was done under the following conditions:

1) Ambient pressure, $\mathrm{Pa}=0.101325 \mathrm{Mpa}$.

2) Exit pressure, $\mathrm{Pe}=0.101325 \mathrm{Mpa}$.

3) Divergent half angle, $\alpha=160$.

4) Combustion chamber pressure, $\mathrm{Pc}=7.0 \mathrm{Mpa}$.

5) Initial temperature, $\mathrm{To}=25 \mathrm{Co}$.

6) Specific heat of the propellant $\mathrm{Cp}=0.226 \mathrm{~kJ} / \mathrm{kg} \cdot \mathrm{K}$

\section{B. Simulation Results}

Two types of nozzle flows ware assumed to determine the chemical compositions of the combustion products along the flow direction: equilibrium flow and frozen flow. For equilibrium flow, the chemical composition of the combustion gas in the nozzle varies with changing pressure and temperature. For frozen flow, no chemical reaction occurs in the nozzle and so the chemical composition remains unchanged throughout the nozzle flow and the temperature of the combustion products decreases in an adiabatic expansion flow. 
TABLE III

SHOW THE RESULT

\begin{tabular}{llllll}
\hline No & \multirow{2}{*}{ Tc } & \multicolumn{2}{l}{ Freeze flow } & \multicolumn{2}{c}{ Equilibrium flow } \\
$\mathrm{s}$ & & $\mathrm{I}_{s p}$ & $\mathrm{C}^{*}$ & $\mathrm{I}_{s p}$ & $\mathrm{C}^{*}$ \\
\hline uni & $\mathrm{K}$ & $\mathrm{N} . \mathrm{s} / \mathrm{kg}$ & $\mathrm{m} / \mathrm{s}$ & $\mathrm{N} . \mathrm{s} / \mathrm{kg}$ & $\mathrm{m} / \mathrm{s}$ \\
F1 & 3525.51 & 2481.79 & 1564.86 & 2547.17 & 1583.35 \\
F2 & 3508.18 & 2488.75 & 1569.92 & 2552.85 & 1588.26 \\
F3 & 3489.53 & 2495.16 & 1574.66 & 2557.93 & 1592.86 \\
F4 & 3448.11 & 2506.33 & 1583.00 & 2566.29 & 1600.89 \\
F5 & 3401.06 & 2514.76 & 1589.64 & 2572.26 & 1607.27 \\
F6 & 3343.01 & 2518.83 & 1593.59 & 2575.94 & 1611.45 \\
F7 & 3244 & 2505.8 & 1587.36 & 2571.87 & 1607.04 \\
\hline
\end{tabular}

\section{Discussion of Simulation Results}

Depending on the data above, the results will be presented according to the effect of RDX percentage mentioned above as shown in the following point.

\section{RDX effect on a Specific Impulse}

For a conventional propellant based on HTPB/AP /AL maximum specific impulse obtained is $2547.17 \mathrm{~N} . \mathrm{s} / \mathrm{kg}$, while for a new oxidizer binder system such as HTPB/AP/RDX /AL, the specific impulse obtained is around (2552.85 to 2575.94) N.s/kg. This clearly indicates the improved performance for a new oxidizer-binder system. As shown in Fig. $1, \mathrm{I}_{s p}$ increases with increasing of RDX in the region percentage of RDX below 0.40 . The maximum $\mathrm{I}_{s p}$ is obtained at about percentage of RDX 0.40, and then decreased with increasing percentage of RDX in the region percentage of RDX above 0.4.

\section{E. RDX Effect on a Characteristic Velocity}

The Characteristic velocity obtained is around (1588.26 to $1611.45) \mathrm{m} / \mathrm{s}$. This clearly indicates the improved performance for a new oxidizer-binder system. As shown in Fig. 2, $C^{*}$ increases with increasing RDX in the region percentage of RDX 0.40 . The maximum $C^{*}$ is obtained at about percentage of RDX (0.40), and then it decreases with increasing percentage of RDX in the region percentage of RDX 0.4 .

\section{F. RDX Effect on a Combustion Temperature}

The Combustion Temperature obtained is around (3508.18 to 3343.01$) \mathrm{m} / \mathrm{s}$. This clearly indicates the improved performance for a new oxidizer-binder system. As shown in Fig. 3, Tc decreases with increasing RDX in the region percentage of RDX 0.40 . The minimum Tc is obtained at about percentage of RDX (0.40).

\section{Conclusion And Recommendations}

\section{A. Conclusion}

From this study the following points can be concluded:

1) The specific impulse and Characteristic velocity can be increased by addition of RDX, but addition above $40 \%$ causes decreasing in the same parameters.

2) RDX can be considered as a good energetic oxidizer and rich source of fuel.

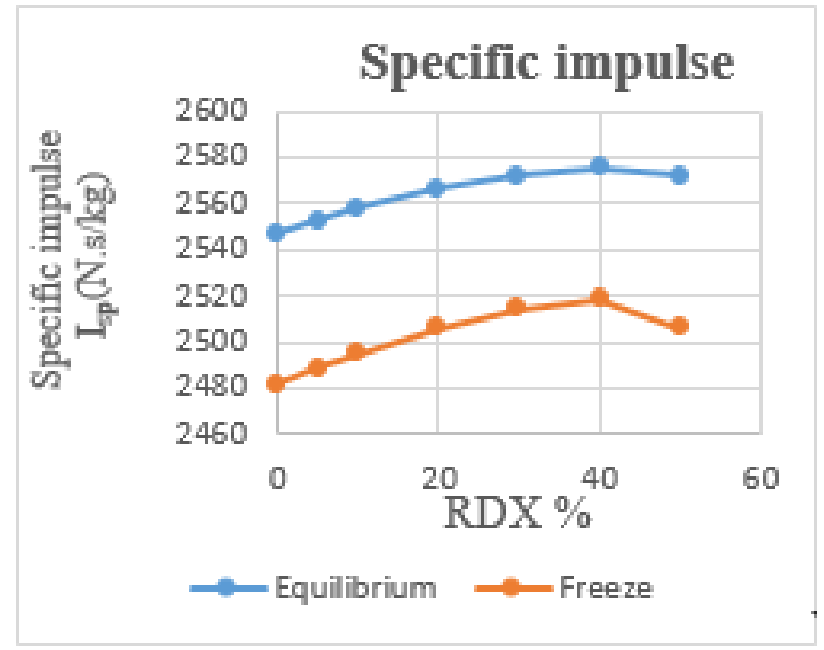

Fig. 1. Shown the Specific impulse.

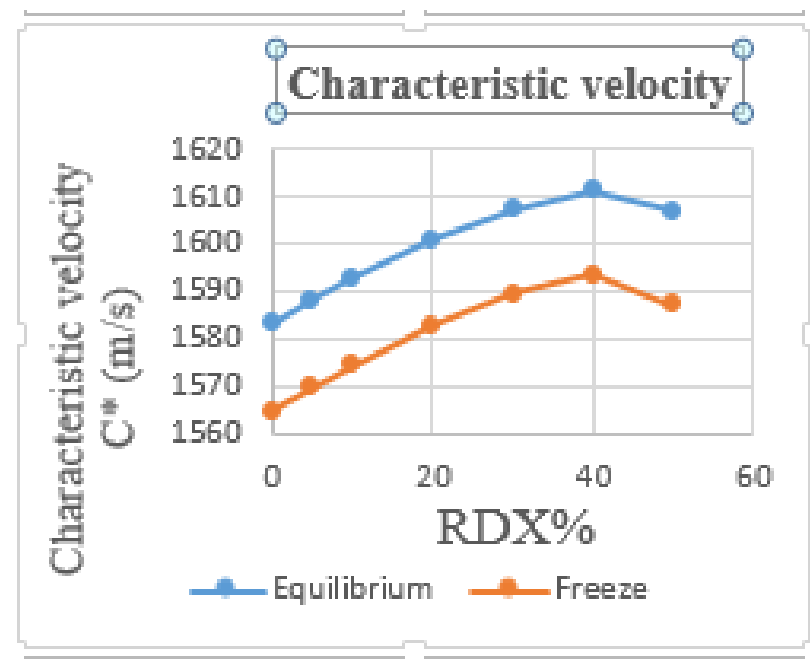

Fig. 2. Shown the Characteristic velocity

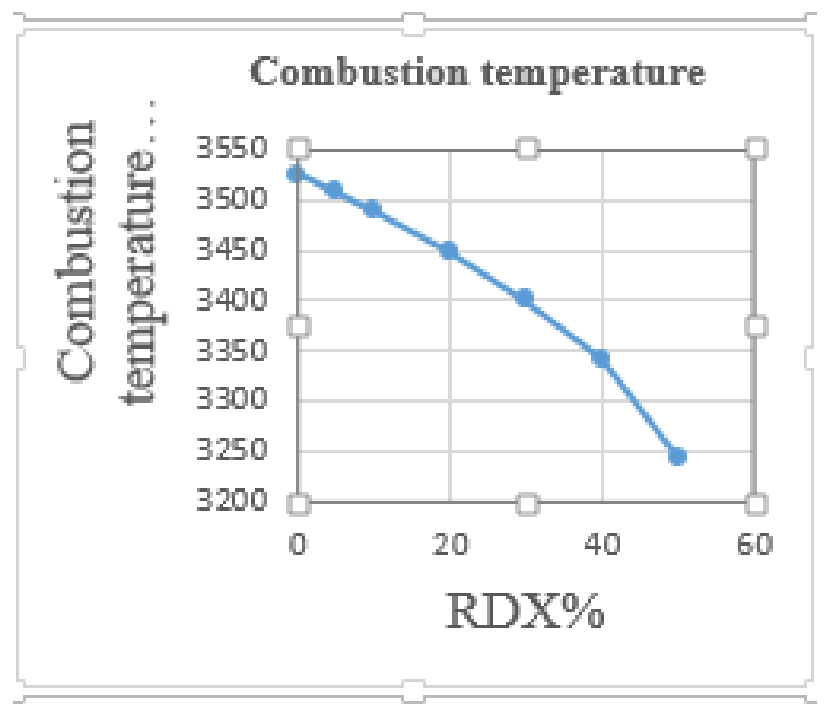

Fig. 3. Shown the Combustion Temperature 
3) Using AP-RDX composite propellant as an energetic oxidizer in propellant formulations may not cause thermal insulation problems because of the low adiabatic flame temperature comparing with those propellant using only AP as an oxidizer.

\section{B. Recommendations}

The following points are recommended for future work: Using the prepared RDX, as an energetic oxidizer in the propellant formulation. Applying this study to the composite propellants and the study of the effect of RDX on the mechanical properties such as tensile, elongation and hardness

\section{REFERENCES}

[1] A. Shteinberg, Fast reactions in energetic materials: high-temperature decomposition of rocket propellants and explosives. Springer Science \& Business Media.

[2] J. Akhavan, The chemistry of explosives. Royal Society of Chemistry.

[3] G. Sutton, "Rocket propulsion elements-an introduction to the engineering of rockets."

[4] S. C. Dsilets, S., "Chemical bond between stabilizers and htpb binders in propellants," Propellants, Explosives, Pyrotechnics, vol. 25, no. 4, p. 186190.

[5] J. Agrawal and R. Hodgson, Organic chemistry of explosives. John Wiley $\&$ Sons.

[6] G. Sutton and O. Biblarz, Rocket propulsion elements. John Wiley \& Sons.

[7] F. P. Hocaolu, . and S. zkar., "Aging of htpb/apbased composite solid propellants, depending on the nco/oh and triol/diol ratios," Journal of applied polymer science, vol. 79, no. 6, p. 959964.

[8] N. Kubota, "Rocket combustion," Nikkan Kogyo Press.

[9] M. Pandey, S. Jha, R. Kumar, S. Mishra, and R. Jha, "The pressure effect study on the burning rate of ammonium nitrate-htpb-based propellant with the influence catalysts," Journal of thermal analysis and calorimetry, vol. 107 , no. 1 , p. 135140 